\title{
Note
}

\section{Effects of Black Rice Containing Anthocyanins on Plasma and Hepatic Parameters in Type 2 Diabetic $d b / d b$ Mice}

\author{
Mitsuru WatANABE* \\ NARO Tohoku Agricultural Research Center, 4 Akahira, Shimokuriyagawa, Morioka, Iwate 020-0198, Japan
}

Received March 7, 2016 ; Accepted June 5, 2016

We examined the effects of black rice (BR) (Oryza sativa L.) grains and an anthocyanin (AC) extract of the grains on lipid and carbohydrate metabolism and in vivo oxidative stress in type 2 diabetic mice. Mice (C57BL/KsJ-lepr ${ }^{d b}$ / lepr $\left.^{d b}, d b / d b\right)$ were fed an AIN-93G based diet containing $20 \%(w / w)$ boiled BR grains or the AC extract $(0.015 \%$ or $\mathbf{0 . 0 3 \%}$, w/w) for 21 days. TBARS levels in the liver tissues of the BR- and AC-diet groups were lower than those of the diabetic control (DC) group. Concentrations of other parameters, such as plasma arteriosclerotic index, hepatic lipids, and total cholesterol in liver tissues in the AC-diet fed group were lower than those in the DC group, and tended to be lower in the BR-diet group than in the DC group. Fecal concentrations of bile acids and cholesterol were higher in the BR- and AC-diet fed groups than in the DC group. These results suggest that compounds in the AC extract contribute to the improvement of lipid metabolism and suppression of in vivo oxidative stress by ingestion of BR grains.

Keywords: black rice, anthocyanin, type 2 diabetic mice, lipid metabolism, oxidative stress

\section{Introduction}

The increasing incidence of metabolic syndrome, which is also a risk factor of diabetes mellitus, is a worldwide issue. In Japan, the number of people strongly suspected of having diabetes was 9.5 million in 2011, and those considered to possibly have diabetes was likely 11 million, according to data from the National Health and Nutrition Survey Japan (MHLW 2012). From the viewpoint of reducing medical costs, it is of interest to investigate some daily staple foods that may help to prevent the onset of and complications arising from type 2 diabetes mellitus. For example, the hypoglycemic and hypolipidemic effects of high-amylose rice in rats (Denardin et al., 2012) and humans (Alison et al., 2015) have been reported.

Boiled rice is a staple of the Japanese diet. Small amounts of black rice (BR) grains, which contain anthocyanins (ACs) in the bran, are occasionally mixed with white rice because of their contribution to health and colorful aesthetics. ACs are widely distributed red, purple, and blue pigments in the plant kingdom. The daily intake of AC is estimated to be $12.5 \mathrm{mg}$ per capita in U.S. adults (Wu et al., 2006), and ranges from $19.8 \mathrm{mg}$ (Bilthoven, the Netherlands) to $64.9 \mathrm{mg}$ (Turin, Italy) in European men and from $18.4 \mathrm{mg}$ (Granada, Spain) to $44.1 \mathrm{mg}$ (Turin, Italy) in women per capita (Zamora-Ros et al., 2011). The high intake of ACs is attributed to the consumption of foods and drinks with high $\mathrm{AC}$ content, such as the berries and wines of the Mediterranean diet in Italy. Recently, powdered BR grains have been used as an ingredient for various colorful processed foods including Japanese sweets. BR is characteristically rich in ACs such as cyanidin 3-glucoside (C3G) and peonidin 3-glucoside (Hiemori et al., 2009). Oral administration of ACs from purple carrot, which contains acylated ACs, in mice subjected to restraint stress revealed in vivo anti-stress effects, such as improvement in lipid metabolism and inhibition of lipid peroxidation (Watanabe and Ayugase, 2008). Um et al. (2013) demonstrated that a C3G-rich extract lowered 
Table 1. Composition of experimental diets"

\begin{tabular}{|c|c|c|c|c|}
\hline Component & $\begin{array}{l}\text { AIN-93G } \\
\text { (control) diet }\end{array}$ & $\begin{array}{c}20 \% \\
\mathrm{BR}^{* *} \text { diet }\end{array}$ & $\begin{array}{c}0.015 \% \\
\mathrm{AC}^{* * *} \operatorname{diet}\end{array}$ & $\begin{array}{c}0.03 \% \\
\text { AC*** diet }\end{array}$ \\
\hline Casein & 20.0 & 18.3 & 20.0 & 20.0 \\
\hline$\beta$ cornstarch & 39.8 & 23.2 & 39.8 & 39.8 \\
\hline$\alpha$ cornstarch & 13.2 & 13.2 & 13.2 & 13.2 \\
\hline Sugar & 10.0 & 10.0 & 10.0 & 10.0 \\
\hline Soybean oil & 7.0 & 6.1 & 7.0 & 7.0 \\
\hline Cellulose & 5.0 & 4.2 & 5.0 & 5.0 \\
\hline $\begin{array}{l}\text { Mineral mix } \\
\text { (AIN-93G) }\end{array}$ & 3.5 & 3.5 & 3.5 & 3.5 \\
\hline $\begin{array}{l}\text { Vitamin mix } \\
\text { (AIN-93G) }\end{array}$ & 1.0 & 1.0 & 1.0 & 1.0 \\
\hline L-Cystine & 0.3 & 0.3 & 0.3 & 0.3 \\
\hline Choline bitartrate & 0.2 & 0.2 & 0.2 & 0.2 \\
\hline $\mathrm{BR}^{* *}$ & - & 20.0 & - & - \\
\hline $\mathrm{AC}^{* * *}$ & - & - & 0.015 & 0.03 \\
\hline
\end{tabular}

*Weight percent. $* * \mathrm{BR}$ : black rice grains (boiled).***AC : anthocyanin extracts from BR

serum cholesterol and triglyceride levels in mice fed a high-fat/ cholesterol diet. In addition, it has been demonstrated that oxidative damage as a result of hyperglycemia is increased in patients with diabetes mellitus (West, 2000). Given that BR is rich in antioxidative phenolic compounds such as ACs and phenolic acids (Laokuldilok et al., 2011), it is presumed to have antidiabetic effects. In the present study, we investigated the effects of BR and constituent ACs on lipid and carbohydrate metabolism in type 2 diabetic mice.

\section{Materials and Methods}

Preparation of boiled black rice (BR) BR (cv. Asamurasaki) grains were produced in Iwate Prefecture, Japan, in 2013. Raw grains (unpolished) were stored at $4^{\circ} \mathrm{C}$ in an airtight plastic bag until cooking. BR grains (375 g) were boiled in distilled water (735 mL) using an electric rice cooker (Sanyo, Tokyo, Japan). Cooked rice was cooled at ambient temperature for $1 \mathrm{~h}$ and stored at $-80^{\circ} \mathrm{C}$. Frozen boiled rice was lyophilized and powdered using a vibrating sample mill. The composition of the powdered boiled BR was as follows $(\mathrm{g} / 100 \mathrm{~g}$ fresh weight): moisture, 4.4; protein, 7.4; fat, 4.5; ash, 1.5; carbohydrate, 78.0; dietary fiber, 4.2. The total $\mathrm{AC}$ content in the powdered BR grains ( $\mathrm{g} / 100 \mathrm{~g}$ fresh weight) was measured by a $\mathrm{pH}$ differential method (Oki et al., 2011).

Changes in antioxidant activity and composition of phenolic compounds (including ACs) during preparation of boiled rice Because rice grains are usually prepared for meals using a rice cooker in Japan, changes in the value of hydrogen radical absorbance capacity (H-ORAC) and phenolic compound composition after preparation of boiled rice were investigated. H-ORAC values of the extract from BR grains before and after boiling were measured according to the method of Watanabe J. et al., (2012). In addition, changes in AC content were measured by the $\mathrm{pH}$ differential method mentioned above, and changes in the composition of phenolic compounds were determined by HPLC. In brief, $0.2 \mathrm{~g}$ of powdered raw BR or cooked BR was mixed with $1 \mathrm{~mL}$ of $80 \%$ methanol and agitated for $3 \mathrm{~h}$ by a shaker. The mixtures were centrifuged at 7,100 $\times \mathrm{g}$ and supernatants were collected. HPLC analysis of phenolic compounds was performed by the same method as previously described (Watanabe M. et al., 2011b).

Preparation of BR- and AC-diets Powdered BR was mixed with AIN-93G diet at a concentration of $20 \%(\mathrm{w} / \mathrm{w})$. Casein, $\beta$-cellulose, and soybean oil were used to adjust protein, dietary fiber, and lipid contents to equal concentrations between the AIN$93 \mathrm{G}$ and $\mathrm{BR}$ diets.

The AC extracts were prepared from BR grains in the same manner as previously described (Watanabe M. et al., 2011b). In brief, $2 \mathrm{~L}$ of $5 \%$ formic acid was added to $100 \mathrm{~g}$ of BR powder and the mixture was stored at $4^{\circ} \mathrm{C}$ for $20 \mathrm{~h}$ with occasional shaking. The extract was centrifuged at $7,100 \times \mathrm{g}$ for $10 \mathrm{~min}$ and the supernatant was collected. The AC fraction was purified by a solid extraction technique using a Sep-Pak C18 cartridge, and the AC content was determined by the $\mathrm{pH}$ differential method mentioned above.

Table 1 lists the composition of the experimental diets. Because the $\mathrm{AC}$ content in the $\mathrm{BR}$ diet was $0.03 \%$, the $\mathrm{AC}$ extract was added at concentrations of $0.03 \%$ and $0.015 \%$ (as the AC diets) to clarify the contribution of ACs to the effects of the BR-diet on lipid metabolism.

Animals Male diabetic $d b / d b\left(\mathrm{C} 57 \mathrm{BL} / \mathrm{KsJ}-\operatorname{lepr}^{d b} / \mathrm{lepr}^{d b}\right)$ and nondiabetic $d b /+\left(\mathrm{C} 57 \mathrm{BL} / \mathrm{KsJ}-m^{+} / \mathrm{epr}^{d b}\right)$ mice were purchased from Japan Clea Inc. (Tokyo, Japan). Animals were housed in plastic cages in a temperature-controlled room $\left(23 \pm 1^{\circ} \mathrm{C}\right)$ under alternating light and dark conditions (12 h each), with free access to water and feed (AIN-93G) until the start of the experiment. At 7 weeks of age, mice were randomly divided into five groups of 7 
Table 2. Changes in contents of anthocyanin, protocatechuic acid, and H-ORAC value in rice with a rice cooker.

\begin{tabular}{lccc}
\hline & $\begin{array}{c}\text { Grains (not boiled) } \\
\text { (A) }\end{array}$ & $\begin{array}{c}\text { Cooked rice } \\
(\mathrm{B})\end{array}$ & $\begin{array}{c}\mathrm{B} / \mathrm{A} \\
(\%)\end{array}$ \\
\hline $\begin{array}{l}\text { Anthocyanin (mg/g dry weight) } \\
\text { Protocatechuic acid (mg/g dry weight) }\end{array}$ & $4.9 \pm 0.0$ & $1.6 \pm 0.0$ & 32.2 \\
$\begin{array}{l}\text { H-ORAC value } \\
(\mu \mathrm{mol} \text { TE equivalent/ g dry weight) }\end{array}$ & $146.8 \pm 4.2$ & $0.26 \pm 0.01$ & \\
\hline
\end{tabular}

Values are mean $\pm \mathrm{SD}$ of 3 experiments. * —: not detected.

mice each. Diabetic mice in the BR group (DBR) were fed a $20 \%$ BR diet based on AIN-93G (Table 1). Diabetic mice in the AC-diet groups were assigned as DLA $(0.015 \%$ AC-diet $)$ and DHA $(0.03 \%$ AC-diet) groups. Diabetic and nondiabetic mice in the control groups, which were assigned to the DC and NC groups, respectively, were fed AIN-93G diet. Blood from the hearts of mice fasted for $15 \mathrm{~h}$ before sacrifice was collected into heparinized tubes under anesthesia by intraperitoneal injection of sodium pentobarbital $(40 \mathrm{mg} / \mathrm{kg}$ body weight) after a 21 day treatment period. Thereafter, the liver and epididymal adipose tissue were sampled, and the HbA1c concentration in whole blood was measured by an immunoassay system (DCA 2000; Siemens, Munich, Germany). Sampled tissues were frozen in liquid nitrogen and stored at $-80^{\circ} \mathrm{C}$ until use. In addition, feces over $24 \mathrm{~h}$ old were collected 6 days before sacrificing the mice. Mice received humane care as outlined in the Guide for the Care and Use of Experimental Animals (NARO Tohoku Agricultural Research Center).

Measurement of plasma glucose After preparation of plasma by centrifugation of the collected blood at $11,000 \times \mathrm{g}$ for $5 \mathrm{~min}$ at $4^{\circ} \mathrm{C}$, plasma glucose levels were measured using a Glucose C-II Test Wako kit (Wako Pure Chemical Industries, Ltd., Osaka, Japan) according to the manufacturer's instructions.

Extraction of lipids from liver tissues Total lipids in the liver tissues were extracted with chloroform-methanol (2: 1; v/v) solvent according to Folch's method (Folch et al., 1957). After removal of the solvent from the extracts, the residue was dissolved in 2-propanol containing 10\% Triton X-100. This crude lipid solution was used for the measurement of lipids.

Measurement of lipids Concentrations of total cholesterol, HDL cholesterol, and triglyceride were respectively measured with the Cholesterol E Test, HDL cholesterol E Test, and triglyceride E Test kits (Wako Pure Chemical Industries, Ltd.).

TBARS Assay for liver tissue and plasma Concentrations of TBARS in the liver tissue homogenates were analyzed using Kikugawa's method (Kikugawa et al., 1992). Plasma TBARS was analyzed according to Yagi's method (1976).

Measurement of protein content in liver homogenate Protein concentrations in liver homogenates were measured using a Protein Quantification Kit-Rapid kit (Dojindo Molecular Technologies, Kumamoto, Japan) according to the manufacturer's instructions.

Measurement of fecal bile acids Collected feces were freeze- dried and ground to a powder using a vibrating mill. Bile acid was extracted from the powder using ethanol at $70^{\circ} \mathrm{C}$ for $1 \mathrm{~h}$. Bile acid levels were determined using the Total Bile Acid Test Wako kit (Wako Pure Chemical Industries, Ltd.) according to the instruction manual.

Measurement of fecal cholesterol Cholesterol was extracted from powdered feces by Folch's method and levels were determined by the Cholesterol E Test as described above.

Statistics Statistically significant differences between groups were evaluated by one-way analysis of variance followed by Tukey's test using Prism 5 software (GraphPad Software Inc., San Diego, CA, USA). $P<0.05$ was considered to be significant.

\section{Results}

The AC content in boiled rice grains $(1.6 \mathrm{mg} / \mathrm{g}$ dry weight) was reduced to $32.2 \%$ of that in the grains before cooking $(4.9 \mathrm{mg} / \mathrm{g}$ dry weight) (Table 2), and $67.8 \%$ of $\mathrm{C} 3 \mathrm{G}$ was lost during the treatment. However, the H-ORAC value of the extract was reduced to $44.4 \%$ (from 146.8 to $65.2 \mu \mathrm{mol}$ TE equivalent/g dry weight) by cooking. Previous investigation of the influence of cooking on the $\mathrm{AC}$ content of $\mathrm{BR}$ revealed that $74.2 \%$ of $\mathrm{C} 3 \mathrm{G}$ was lost when the rice cooker was used (Hiemori et al., 2009). Although cooking conditions, such as temperature, pressure and time, between rice cookers may not have been identical, a large amount of $\mathrm{C} 3 \mathrm{G}$ in $\mathrm{BR}$ was lost by cooking in both studies. HPLC analysis of the extract from boiled BR showed that protocatechuic acid $(0.26 \mathrm{mg} / \mathrm{g}$ dry weight) was generated as a cleavage product of $\mathrm{C} 3 \mathrm{G}$ during the preparation of boiled rice, as shown by Hiemori et al. (2009).

Table 3 gives the food intake, final body weight, body weight gain, liver weight, and epididymal adipose tissue weight of $d b /+$ (NC group) and $d b / d b$ (DC, DBR, DLA, and DHA groups) mice. Although the food intake of the diabetic groups was higher than that of the nondiabetic groups, there were no significant differences among the diabetic groups. After the 21 day feeding period, final body weight and body weight gain of the diabetic groups were higher than those of the nondiabetic groups. There were no differences in the final body weight, body weight gain, liver weight, or epididymal adipose tissue weight among the diabetic mice groups.

Effects of the BR diet on blood and plasma parameters are shown in Table 4. The plasma glucose concentration in the diabetic 
Table 3. Food intake, final body weight, body weight gain, liver weight, and an epididymal fat tissue of $d b /+(\mathrm{NC}$ group) and $d b / d b$ (DC, DBR, DLA, and DHA groups) mice.

\begin{tabular}{lrrrrr}
\hline \multicolumn{1}{c}{ Dietary group } & \multicolumn{1}{c}{ NC } & \multicolumn{1}{c}{ DC } & \multicolumn{1}{c}{ DBR } & \multicolumn{1}{c}{ DLA } & \multicolumn{1}{c}{ DHA } \\
\hline Food intake (g/d) & $3.7 \pm 0.4^{\mathrm{b}}$ & $5.8 \pm 0.6^{\mathrm{a}}$ & $5.6 \pm 0.7^{\mathrm{a}}$ & $5.8 \pm 0.7^{\mathrm{a}}$ & $5.6 \pm 0.6^{\mathrm{a}}$ \\
Final body-wt (g) & $25.4 \pm 0.6^{\mathrm{b}}$ & $42.0 \pm 1.2^{\mathrm{a}}$ & $43.0 \pm 2.3^{\mathrm{a}}$ & $42.2 \pm 0.8^{\mathrm{a}}$ & $41.0 \pm 2.4^{\mathrm{a}}$ \\
Body-wt. gain (g/21 d) & $3.1 \pm 0.8^{\mathrm{b}}$ & $11.6 \pm 1.6^{\mathrm{a}}$ & $12.4 \pm 1.1^{\mathrm{a}}$ & $11.5 \pm 1.1^{\mathrm{a}}$ & $10.7 \pm 2.2^{\mathrm{a}}$ \\
Liver-wt. (g/100 g body wt.) & $3.9 \pm 0.1^{\mathrm{b}}$ & $5.8 \pm 0.7^{\mathrm{a}}$ & $5.2 \pm 0.4^{\mathrm{a}}$ & $5.2 \pm 0.4^{\mathrm{a}}$ & $5.3 \pm 0.4^{\mathrm{a}}$ \\
Epididymal adipose tissue-wt. & $0.7 \pm 0.2^{\mathrm{b}}$ & $2.5 \pm 0.2^{\mathrm{a}}$ & $2.5 \pm 0.2^{\mathrm{a}}$ & $2.4 \pm 0.2^{\mathrm{a}}$ & $2.2 \pm 0.2^{\mathrm{a}}$ \\
(g/100 g body wt.) & & & & & \\
\hline
\end{tabular}

Values are mean $\pm \mathrm{SE}$ of 7 mice. Different superscript letters indicate significant differences $(P<0.05)$. NC, nondiabetic control (AIN-93G) group; DC, diabetic control (AIN-93G) group; DBR, diabetic BR group; DLA, diabetic $0.015 \%$ AC group; DHA, diabetic $0.03 \%$ AC group.

Table 4. Blood and plasma parameters of $d b /+$ (NC group) and $d b / d b$ (DC, DBR, DLA, and DHA groups) mice.

\begin{tabular}{lccccc}
\hline \multicolumn{1}{c}{ Dietary group } & NC & DC & DBR & DLA & DHA \\
\hline HbAlc (\%) & $3.8 \pm 0.1^{\mathrm{b}}$ & $8.5 \pm 1.1^{\mathrm{a}}$ & $8.1 \pm 0.7^{\mathrm{a}}$ & $8.4 \pm 0.6^{\mathrm{a}}$ & $8.3 \pm 0.7^{\mathrm{a}}$ \\
Plasma glucose (mg/dL) & $139 \pm 31^{\mathrm{b}}$ & $736 \pm 118^{\mathrm{a}}$ & $735 \pm 99^{\mathrm{a}}$ & $759 \pm 61^{\mathrm{a}}$ & $760 \pm 75^{\mathrm{a}}$ \\
Total cholesterol (mg/dL) & $68 \pm 2^{\mathrm{b}}$ & $131 \pm 4^{\mathrm{a}}$ & $131 \pm 2^{\mathrm{a}}$ & $124 \pm 7^{\mathrm{a}}$ & $116 \pm 4^{\mathrm{a}}$ \\
HDL cholestrol (mg/dL) & $48 \pm 2^{\mathrm{b}}$ & $77 \pm 2^{\mathrm{a}}$ & $81 \pm 2^{\mathrm{a}}$ & $78 \pm 5^{\mathrm{a}}$ & $77 \pm 3^{\mathrm{a}}$ \\
Arteriosclerotic index** & $0.42 \pm 0.02^{\mathrm{d}}$ & $0.71 \pm 0.01^{\mathrm{a}}$ & $0.63 \pm 0.03^{\mathrm{ab}}$ & $0.60 \pm 0.02^{\mathrm{bc}}$ & $0.52 \pm 0.03^{\mathrm{c}}$ \\
\hline
\end{tabular}

Values are mean \pm SE of 7 mice. Different superscript letters indicate significant differences $(P<0.05)$. $\mathrm{NC}$, nondiabetic control (AIN-93G) group; DC, diabetic control (AIN-93G) group; DBR, diabetic BR group; DLA, diabetic $0.015 \%$ AC group; DHA, diabetic $0.03 \%$ AC group. *analyzed with whole blood. ** Arteriosclerotic index: (total cholesterol - HDL cholesterol)/HDL cholesterol.

Table 5. Hepatic lipids of $d b /+$ (NC group) and $d b / d b$ (DC, DBR, DLA, and DHA groups) mice.

\begin{tabular}{lcclcc}
\hline \multicolumn{1}{c}{ Dietary group } & NC & DC & \multicolumn{1}{c}{ DBR } & \multicolumn{1}{c}{ DLA } & DHA \\
\hline Lipids (mg/g tissue) & $46 \pm 5^{\mathrm{c}}$ & $152 \pm 14^{\mathrm{a}}$ & $119 \pm 8^{\mathrm{ab}}$ & $104 \pm 6^{\mathrm{b}}$ & $107 \pm 9^{\mathrm{b}}$ \\
Total cholesterol (mg/g tissue) & $2.4 \pm 0.1^{\mathrm{c}}$ & $8.7 \pm 0.3^{\mathrm{a}}$ & $7.8 \pm 0.4^{\mathrm{ab}}$ & $8.0 \pm 0.1^{\mathrm{ab}}$ & $7.0 \pm 0.4^{\mathrm{b}}$ \\
Triglyceride & $39 \pm 6^{\mathrm{b}}$ & $124 \pm 8^{\mathrm{a}}$ & $113 \pm 7^{\mathrm{a}}$ & $105 \pm 8^{\mathrm{a}}$ & $97 \pm 7^{\mathrm{a}}$ \\
\hline
\end{tabular}

Values are mean $\pm \mathrm{SE}$ of 7 mice. Different superscript letters indicate significant differences $(P<0.05)$. $\mathrm{NC}$, nondiabetic control (AIN-93G) group; DC, diabetic control (AIN-93G) group; DBR, diabetic BR group; DLA, diabetic $0.015 \%$ AC group; DHA, diabetic $0.03 \%$ AC group.

groups was higher than in the nondiabetic group. There were no differences in plasma glucose concentration among the diabetic groups. In addition, there were no differences in the $\mathrm{HbA} 1 \mathrm{c}$ concentration, which is an index of persistent hyperglycemia, among the diabetic groups.

Concentrations of total cholesterol and HDL cholesterol, and the arteriosclerotic index [(total cholesterol - HDL cholesterol)/ HDL cholesterol], in the plasma are also shown in Table 4. Although the concentration of plasma total cholesterol was significantly higher in the DC group than in the NC group, there were no significant differences among the diabetic groups. Concentrations of HDL cholesterol in the DC, DBR, DLA, and DHA groups were higher than in the NC group, and there were no significant differences among the diabetic groups. The arteriosclerotic index was substantially lower in the diabetic ACfed groups (DLA and DHA) than in the DC group. There were no significant differences between the DBR and AC-fed groups.

The effects of BR and ACs on hepatic lipids are shown in
Table 5. The level of hepatic lipids in the DC group was higher than that in the $\mathrm{NC}$ group, but levels were significantly lower in the diabetic AC-fed groups (DLA and DHA) than in the DC group. In addition, cholesterol levels in the DBR and DLA groups were significantly lower than in the DC group.

To confirm the mechanism of suppression of plasma arteriosclerotic index and cholesterol level in the liver tissue, the fecal concentrations of bile acids and cholesterol were determined (Figure 1). The 0.03\% AC-diet (DHA group) and 20\% BR-diet (DBR group) showed significantly increased fecal bile acid concentration. In addition, the BR-diet significantly increased the fecal cholesterol concentration, while there were no differences in the DC and AC-fed groups.

TBARS concentrations in the plasma and liver tissue are shown in Figure 2. Lipid peroxidation in both the plasma and liver tissue was elevated in the DC group compared to the NC group. In contrast, the BR- and AC-diets significantly suppressed hepatic TBARS concentrations. 
A

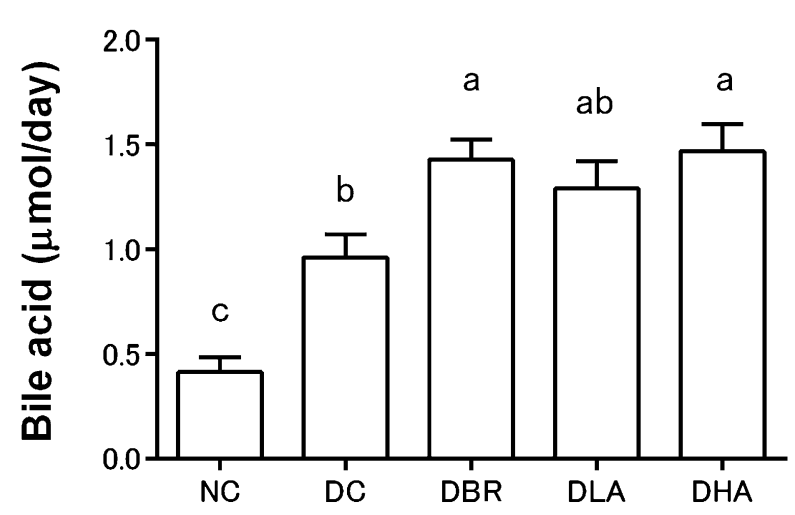

B

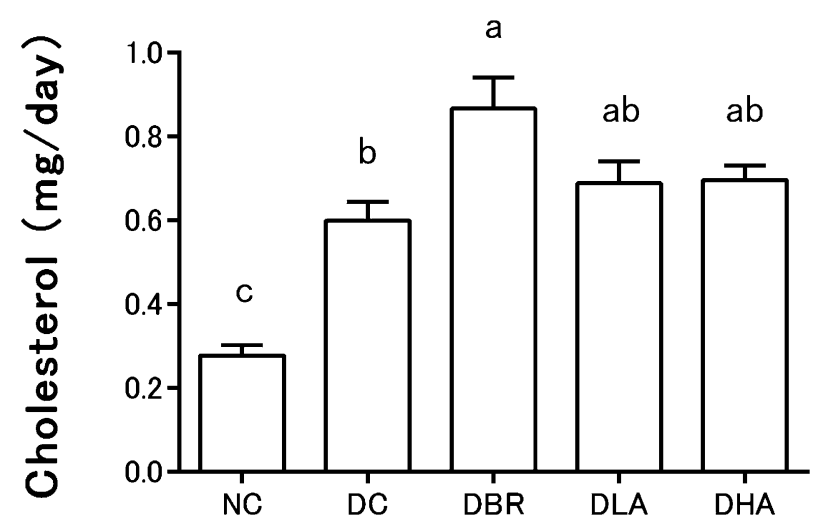

Fig. 1. Effects of BR grains or anthocyanin extracts from BR on bile acid and cholesterol concentration in feces. NC, nondiabetic control (AIN-93G) group; DC, diabetic control (AIN-93G) group; DBR, diabetic $20 \%$ BR group; DLA, diabetic $0.015 \%$ AC group; DHA, diabetic $0.03 \%$ AC group. Data are mean $\pm \mathrm{SE}(\mathrm{n}=7)$. Different letters indicate significant differences $(P<0.05)$.

\section{Discussion}

BR (Farder et al., 2008) and brown rice (Wu et al., 2013) grains are rich in phenolic compounds having antioxidant activity. These grains are utilized as staple foods, with the expectation that their in vivo antioxidant activity will contribute to health. Given the utilization of BR in daily foods such as mixed rice, in this study, we prepared diets (based on AIN-93G) containing 20\% boiled BR grains for type 2 diabetic $d b / d b$ mice. Although $\mathrm{BR}$ grains are rich in ACs such as $\mathrm{C} 3 \mathrm{G}$ and a small amount of peonidin 3-glucoside, much of the $\mathrm{C} 3 \mathrm{G}$ in the grains was lost by cooking. However, $44.4 \%$ of the H-ORAC value of raw grains was maintained in the boiled grains due to the presence of $\mathrm{C} 3 \mathrm{G}$ (32.2\% before cooking) and protocatechuic acid, a product of $\mathrm{C} 3 \mathrm{G}$ cleavage during cooking. Therefore, boiled BR grains in daily meals are expected to be a source of phenolic compounds with antioxidant activity.

We also prepared $0.03 \%$ and $0.015 \%(\mathrm{w} / \mathrm{w}) \mathrm{AC}$ diets, since the AC content in the $20 \%$ BR-diet was $0.03 \%$. The AC-diet improved lipid metabolism, evidenced by the reduction in the plasma arteriosclerotic index and hepatic cholesterol level of $d b / d b$ mice,
A
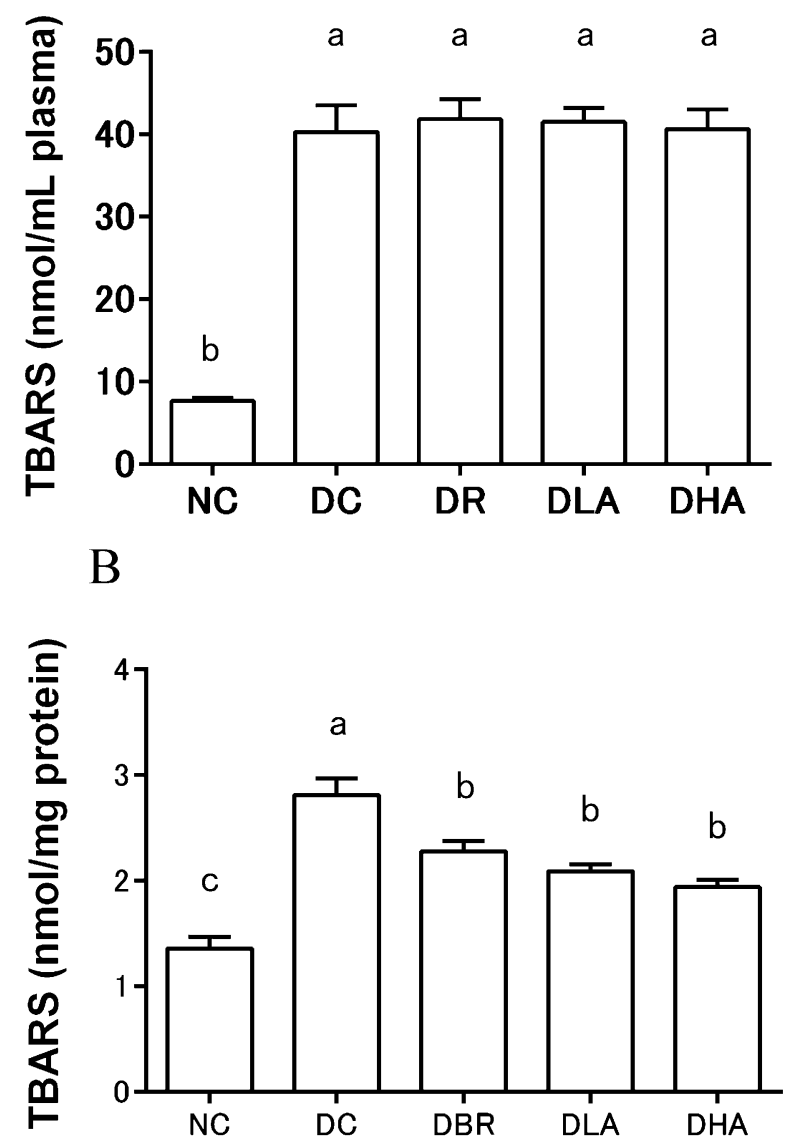

Fig. 2. Effects of BR grains or anthocyanin extracts from BR on lipid peroxidation in plasma (A) and liver tissues (B) in mice. NC, nondiabetic control (AIN-93G) group; DC, diabetic control (AIN93G) group; DBR, diabetic 20\% BR group; DLA, diabetic $0.015 \%$ AC group; DHA, diabetic $0.03 \%$ AC group. Data are mean $\pm \mathrm{SE}$ (n $=7)$. Different letters indicate significant differences $(P<0.05)$.

while the BR-diet tended to improve these parameters in diabetic mice. On the other hand, fecal bile acids were significantly increased in the DBR (boiled BR-diet) and DHA (0.03\% AC-diet) groups. Previously, we demonstrated that oral administration of acylated AC from black carrot (Daucus carota L.+), once per day at $20 \mathrm{mg} / \mathrm{kg}$ body weight for 3 days, significantly reduced the plasma arteriosclerotic index and tended to reduce the hepatic cholesterol level in mice subjected to restraint stress (Watanabe M. et al., 2011b). Moreover, the hypolipidemic activity of C3G $(0.06 \%$ in the diet for 12 weeks) in apo-E deficient mice has been reported (Xia et al., 2003). This effect was ascribed to the upregulation of expression of cholesterol 7- $\alpha$-hydroxylase (CYP7A1), which is the rate-limiting enzyme for bile acid synthesis in liver (Wang et al., 2012). These results suggest that the $0.03 \%$ AC-diet increased hepatic synthesis of bile acids, which were then excreted in the feces, thereby contributing to the improvement of lipid metabolism in $d b / d b$ mice. The effect of the $20 \%$ BR-diet on lipid metabolism could largely be ascribed to the hypolipidemic effect of the $\mathrm{C} 3 \mathrm{G}$ (i.e., AC) contained in the diet. In addition, protocatechuic acid in 
the BR-diet may have an additive effect on lipid metabolism by its hypolipidemic activity, such as an increase in lipid profile and decrease in HDL-cholesterol (Harini and Pugalendi, 2010). The difference in the effects of the BR- and AC-diets may be ascribed to differences in the absorption rate of $\mathrm{AC}$ in the two diets; that is, the absorption rate of purified AC may be higher than the unpurified $\mathrm{AC}$ in the BR-diet. Although fecal cholesterol levels in the AC-fed groups did not differ from the DC group, the level in the DBR group was significantly higher than in the DC group. This suggests that a small amount of soluble dietary fiber or other components in unpolished BR facilitates the fecal excretion of cholesterol. Earlier, we analyzed the gene expression of cholesterol metabolism enzymes, such as hydroxymethylglutaryl CoA (HMG$\mathrm{CoA}$ ), which is the rate-limiting enzyme in cholesterol synthesis, along with CYP7A1 in $d b / d b$ mice fed $20 \%$ millet (Japanese barnyard millet and adlay) diets and demonstrated enhancement of CYP7A1 gene expression by these grains (Watanabe M. et al., 2011a). Because the quality of hepatic total RNA from mice in these experiments was not sufficient for gene expression analysis of enzymes involved in lipid metabolism, such as HMG-CoA and CYP7A1, further studies should be performed to clarify the hypolipidemic effect of BR grains and constituent ACs.

Hypoglycemic activity, such as suppression of blood glucose level and insulin sensitivity, of $\mathrm{C} 3 \mathrm{G}(0.2 \%$ in feed, w/w) in type 2 diabetic KK-A $\mathrm{A}^{\mathrm{y}}$ mice has been reported (Sasaki et al., 2007). However, feeding of the BR- or AC-diet had no effect on the HbA1c concentration in whole blood of $d b / d b$ mice, suggesting that the hypoglycemic effects of BR- and AC-diets in $d b / d b$ mice would not be expected for the AC-diet $(0.03 \%$ or $0.015 \%)$ in this study.

Increased in vivo oxidative stress in blood and tissues is observed in diabetic patients compared with healthy individuals. Although the BR- and AC-diets had no effect on plasma TBARS levels in diabetic mice, these diets suppressed hepatic TBARS levels in diabetic mice compared to control diet mice. Although there were no significant differences in the DBR, DLA, and DHA groups, the TBARS level of the DBR group tended to be higher than the DHA group, suggesting that the absorption rate of isolated ACs might be higher than for ACs remaining in the grains. We also demonstrated that acylated ACs from black carrot substantially inhibited lipid peroxidation in liver tissues of mice subjected to restraint stress (Watanabe M. et al., 2011b). These results suggest that ACs in BR grains could act as antioxidants against the generation or elevation of reactive oxygen species in the liver tissues of diabetic mice.

The BR-diet showed effects on lipid metabolism along with in vivo antioxidant activity in type 2 diabetic mice. These results indicate that cooked BR grains containing ACs would be useful as a daily food, due to the expected health-benefits of their antidiabetic activity.

\section{Conclusion}

The hypolipidemic effects of the BR- and AC-diets in type 2 diabetic mice were mainly attributable to the facilitation of bile acids synthesis in the liver tissues and their subsequent fecal excretion. In addition, BR- and AC-diets revealed in vivo antioxidative activity, which was mainly due to $\mathrm{C} 3 \mathrm{G}$, as observed by the suppression of hepatic TBARS levels.

Acknowledgments This work was supported by a grant from the Ministry of Agriculture, Forestry, and Fisheries of Japan for the project "Development of Evaluation and Management Methods for Supply of Safe, Reliable, and Functional Food and Farm Produce."

\section{References}

Alison, M. and Stewart, M.L. (2015). High amylose white rice reduces post-prandial glycemic response but not appetite in humans. Nutrients, 7 , 5362-5374; doi: 10.3390/nu7075225.

Denardin, C.C., Boufleur, N., Reckziegel, P., da Silva, L.P., and Walter, M. (2012). Amylose content in rice (Oryza sativa) affects performance, glycemic and lipidemic metabolism in rats. Ciencia Rural, 42, 381-387.

Farder, A., Rock, E., and Remesy C. (2008). Is the in vitro antioxidant potential of whole-grain cereals and cereal products well reflected in vivo? J. Cereal Sci. 48, 258-276.

Folch, J., Lees, M., and Stanley, G.H.S. (1957). A simple method for isolation and purification of total lipid from animal tissues. J. Biol. Chem. 226, 497-509.

Harini, R. and Pugalendi K.V. (2010). Antioxidant and antihyperlipidaemic activity of protocatechuic acid on streptozotocin-diabetic rats. Redox Rep., 15, 71-80.

Hiemori, M., Koh, E., and Mitchell, A.E. (2009). Influence of cooking on anthocyanins in black rice (Oryza sativa L. japonica var. SBR). J. Agric. Food Chem., 57, 1908-1914.

Kikugawa, K., Kojima, T., Yamaki, S., andb Kosugi, H. (1992). Interpretation of the thiobarbituric acid reactivity of rat liver and brain homogenates in the presence of ferric ion and ethylenediaminetetraacetic acid. Anal. Biochem., 202, 249-255.

Laokuldilok, T., Shoemaker, C.F., Jongkaewwattana, S., and Tulyathan, V. (2011). Antioxidants and antioxidant activity of several pigmented rice brans. J. Agric. Food Chem., 59, 193-199.

Oki, T., Sawai, Y., Sato-Frukawa, M., and Suda, I. (2011). Validation of $\mathrm{pH}$ differential method for the determination of total anthocyanin content in black rice and black soybean with interlaboratory comparison. Bunseki Kagaku, 60, 819-824.

Sasaki, R., Nishimura, N., Hoshino, H., Isa, Y., Kadowaki, M., Ichi, T., Tanaka, A., Nishiumi, S., Fukuda, I., Ashida, H., Horio, F., and Tsuda, T. (2007). Cyanidin 3-glucoside ameliorates hyperglycemia and insulin sensitivity due to downregulation of retinol binding protein 4 expression in diabetic mice. Biochem. Pharm., 74, 1619-1627.

Um, M.Y., Ahn J., and Ha, T.Y. (2013). Hypolipidaemic effects of cyanidin 3-glucoside rich extract from black rice through regulating hepatic lipogenic enzyme activities. J. Sci. Food Agric., 93, 3126-3128. 
Wang, D., Xia, M., Gao, S., Li, D., Zhang, Y., Jin, T., and Ling, W. (2012). Cyanidin3-O- $\beta$-glucoside upregulates hepatic cholesterol $7 \alpha$-hydroxylase expression and reduces hypercholesterolemia in mice. Mol. Nutr. Food Res., 56, 610-621.

Watanabe, J., Oki, T., Takebayashi, J., Yamasaki, K., Takano-Ishikawa, Y., Hino, A., and Yasui, A. (2012). Method validation by interlaboratory studies of improved hydrophilic oxygen radical absorbance capacity methods for the determination of antioxidant capacities of antioxidant solutions and food extracts. Anal. Sci., 28, 159-165.

Watanabe, M. and Ayugase, J. (2008). Anti-stress effects of flavonoids from buckwheat sprouts in mice subjected to restraint stress. Food Sci. Technol. Res., 14, 253-260.

Watanabe, M., Kato, M., and Ayugase, J. (2011a). Effects of millet grain administration on lipid metabolism in type 2 diabetic $\mathrm{db} / \mathrm{db}$ mice. Nippon Shokuhin Kagaku Kogaku Kaishi, 58, 476-482.

Watanabe, M., Musumi, K., and Ayugase, J. (2011b). Effect of pigment extracts from purple carrot (Dacus carota, L.) on the reactions in mice subjected to restraint stress. Nippon Shokuhin Kagaku Kogaku Kaishi, 58, 7-15.

West, IC. (2000). Radicals and oxidative stress in diabetes. Diabetic Medicine, 17, 171-180.

Wu, F., Chen, H., Yang, N., Wang, J., Duan, X.D., and Jin, Z. (2013).
Effect of germination time on physicochemical properties of brown rice flour and starch from different rice cultivars. J. Cereal Sci., 58, 263-271.

Wu, X., Beecher, G.R., Holden, J.M., Haytowitz, D.B., Gebhardt, S.E., and Prior, R.L. (2006). Concentration of anthocyanins in common foods in the United States and estimation of normal consumption. J. Agric. Food Chem., 54, 4069-4075.

Yagi, K. (1976). A simple fluorometric assay for lipoperoxide in blood plasma. Biochem. Med., 15, 212-216.

Xia, M., Ling, H.L., Ma, J., Kitts, D.D., and Zawistowski, J. (2003). Supplementation of diets with the black rice pigment fraction attenuates atherosclerotic plaque formation in apolipoprotein $\mathrm{E}$ deficient mice. $J$. Nutr., 133, 744-751.

Zamora-Ros, R., Knaze, V., Lujan-Barrosso, I., Slimani, N., Romieu, I., Fedirko, V., and deMagistris, M.S., (2011). Estimated dietary intakes of flavonols, flavanones, and flavones in the European prospective investigation into cancer and nutrition (EPIC) 24-hour dietary recall cohort. Br J. Nutr., 106, 1915-1925.

\section{URL cited}

[MHLW] Ministry of Health, Labor and Welfare of Japan. 2012. Outline for the results of the National Health and Nutrition Survey Japan, 2011. i) http://www0.nih.go.jp/eiken/english/research/pdf/nhns2011_outline.pdf 